Article

\title{
Dynamic Evolution of Venture Capital Network in Clean Energy Industries Based on STERGM
}

\author{
Chen Zhang ${ }^{1}$, Xinghua Dang ${ }^{1}$, Tao Peng ${ }^{2, *}$ and Chaokai Xue ${ }^{1}$ \\ 1 School of Economics and Management, Xi'an University of Technology, Xi'an 710054, China; \\ 1150510002@stu.xaut.edu.cn (C.Z.); gsg1001@xaut.edu.cn (X.D.); 1160511009@stu.xaut.edu.cn (C.X.) \\ 2 International School of Business \& Finance, Sun Yat-sen University, Zhuhai 519082, China \\ * Correspondence: zhansheng91@126.com
}

Received: 11 October 2019; Accepted: 6 November 2019; Published: 11 November 2019

check for updates

\begin{abstract}
This paper provides a detailed description of venture capital (VC) investments in clean energy industries in China over the period 2006-2017 and explores the evolution of clean energy industry VC networks through network formation and network dissolution. Results from the separable temporal exponential-family random graph model (STERGM) show that the factors vary in their relative importance for clean energy industry VC network formation and dissolution. Specifically, governmental venture capital (GVC) and geographic proximity have strong impacts on the formation of networks but not on their dissolution. Reputation and structural embeddedness promote the formation of networks and inhibit their dissolution, and cognitive proximity is found to cause network formation while facilitating network dissolution. The results provide practical and theoretical guidance for the network development of VC firms investing in clean energy industries.
\end{abstract}

Keywords: clean energy; venture capital; syndication; network evolution

\section{Introduction}

Clean energy startups face a so-called "valley of death" between starting an entrepreneurial firm and large-scale deployment of its products and services [1] owing to tremendous investment, long period, high risk, and high levels of uncertainty [2,3]. To obtain sufficient outside financing, clean energy startups frequently turn to venture capital (VC) firms with high failure tolerance and risk preference to finance the early and high-risk stages of commercialization. As syndicated investments help VC firms to reduce financial pressure, share the risks, and restrict outside investors [4], VC firms are more inclined to adopt the syndication strategy and formulate networks-when two or more VC firms jointly undertake a new project [5] — to invest in clean energy startups. Therefore, our research question is which factors determine the structure of a clean energy industry VC network.

This paper aims to first explain the different factors that impact VC network formation and network dissolution in clean energy industries. Network development is a prominent feature of the VC industry [5], and VC networks are critical to the rise and development of clean energy industries [6]. VC firms can not only search investment opportunities through a clean energy industry VC network [7], but also use the network to integrate the expertise and human resources of clean energy startups to attract more VC firms into clean energy industries [4]. Despite the popularity of VC syndicated investments in clean energy industries, we still know relatively little about how clean energy industry VC networks evolve. In addition, there are many theoretical and empirical studies on VC network formation [8-10], but there have been few rigorous studies that explore how VC networks dissolve, especially in clean energy industries. Actually, network evolution involves the sequential processes of network formation and dissolution [6,8,11]; moreover, different factors might drive each process and the formation and dissolution of a network are not generally strictly inverse mechanisms [12,13]. 
To understand how the clean energy industry VC network evolves, we empirically investigate the dynamics of China's clean energy industry VC network using 292 domestic rounds of syndication investment made by Chinese VC firms during 2006-2017. As VC network formation and network dissolution are simultaneously determined, we apply the separable temporal exponential-family random graph model (STERGM) method into our empirical study. As a recently recognized network dynamic analysis methodology, the STERGM separates the network formation and dissolution processes, allows for the accurate designation of multiple processes that affect the dynamics of the network structure, and does not need the independent assumption that the traditional regression models need. Results show that the factors vary in their relative importance for clean energy industry VC network formation and dissolution, indicating that the process of network formation and dissolution are not mirror images of each other. Specifically, governmental venture capital (GVC) and geographic proximity have strong impacts on the formation of networks but not on their dissolution. Reputation and structural embeddedness promote the formation of networks and inhibit their dissolution, and cognitive proximity is found to cause network formation while facilitating network dissolution.

Our paper first provides a detailed description of the dynamics of a VC network in clean energy industries. Prior research suggests that investment risk and portfolio company quality has a significant effect on VC network formation [10]. Our results are distinct from prior studies in that we find VC firm characteristics, the proximity between VC firms, and network structural characteristics are also important determinants of network formation and network dissolution. When designing the syndication investment structure in clean energy industries, VC firms should cooperate with high-reputable investors or form a closed triad structure to enhance network stability and the chances of successful exits. In addition, when syndicating with cognitive proximity partners, VC firms need to pay more attention to the impact of relationship instability.

We take the Chinese VC industry as the empirical backdrop for the following reasons. First, as the world's largest energy producer and consumer, China is also one of the global leaders for clean energy VC investments. China's development of the clean energy industry and upgrade in energy structure are crucial for mitigating global climate issues and global economic and social sustainable development [14]. Furthermore, under the dual pressures of domestic environmental protection and the international climate agreement, China has realized the importance of establishing a clean, low-carbon safe, and efficient energy system based on clean energy. The Chinese government has issued a number of policies supporting the development of clean energy technology and a market that is supportive of the development of a clean energy industry. Third, the Chinese VC industry is characterized by government intervention and newly established, constantly changing institutions. In this type of high-uncertainty environment, VC firms seek syndications to hedge against various types of risks. Building "guanxi", which is defined as "a high-trust relationship which is relatively independent of the social structure around it", is a common strategy for VC firms in this industry [8].

This paper makes four major contributions. First, we contribute to the literature on VC syndication formation. We offer a much more complete perspective than prior VC syndication literature, which focuses on syndication formation at the level of the individual deal $[11,15]$ by highlighting the networks formed from the aggregation of syndicate deals. Prior research has long examined the different firmand dyad-specific factors of VC syndication formation. However, there has been little empirical work that has explored the endogenous network structural processes.

Second, we extend the VC network evolution literature by simultaneously studying network formation and dissolution, thus remedying the lack of investigation on network dissolution and providing a relatively complete picture for the network evolution. The existing research on VC network evolution mainly focuses on the key factors for the relationship formation between VCs; however, there are very limited empirical evidences and few theoretical arguments regarding what factors determine relationship dissolution or persistence [16].

Third, our study extends the role of the government in the development of clean energy industries in emerging economies. The government can operate indirectly through renewable energy and climate 
policies to make clean energy startups attractive [17] and by directly setting up GVC firms [18] or using the status of GVC to attract more private VC (PVC) firms into the clean energy industry by forming network relationships [19].

Lastly, this paper contributes to the literature on the risk finance of new energy companies. Outside financing is very essential for promoting clean energy technology entrepreneurship [20]. Existing studies point out that government funding program or tax credits could provide capital for new energy companies [21-23]. Our research shows that syndication investments are other effective financing channels for new energy companies to seek capital.

The rest of the paper is organized as follows: Section 2 introduces the literature review; Section 3 provides the theoretical development and hypotheses; Section 4 introduces the STERGM approach; Section 5 discusses the research design; Section 6 presents the empirical results; Section 7 provides the discussion; and Section 8 includes the conclusions and policy implications.

\section{Literature Review}

\subsection{VC Network Evolution}

Syndication is formed when two or more VC firms take an equity stake in a start-up for a joint pay-off at the same time. Many VC firms are involved in syndicated investment with numerous VC partners across a range of start-ups, creating a chain of investments in which the syndications form the links. A VC network, therefore, is defined as a dynamic network formed by the accumulation of syndications, new entrants join the network and new ties are formed, while old firms exit the network and old ties might be maintained or dissolved [7].

Existing research on VC networks mostly focuses on the characteristics of static VC networks and their effects. The black box of the process of venture capital network evolution has not been solved [8]. The essence of the evolution of venture capital networks is the choice of partners and the resulting formation and dissolution of partnerships [6,8]. On the one hand, based on resources demand, such as project information and network status, VC firms will select suitable syndication partners to build network relationships. Based on the Braudel theory, Kogut et al. [7] found that the demand of trust and diversity encouraged VC firms to choose syndication partners and revealed the dynamic evolution of the United States (US) VC network. Sorenson and Stuart [6] found that the demand for emerging projects has promoted the formation of long-distance network relationships among VC firms and their impact on the evolution of VC network structures. On the other hand, in view of the limited resources and attention, VC firms will choose to dissolve some low-value or redundant relationships, and the partners of them are unstable. Bubna et al. [24] studied the dynamic evolution of the US VC network and found that VC firms only maintain network relationships with a few valuable partners and the network relationships with most of the partners are dissolved, pointing out that this is the basis of the community structure. Existing research pays less attention to the process of network relationship dissolution, which is one of the research gaps pointed out by many scholars [25]. Only a few studies focus on the dissolution of network relationships, such as the termination of alliance network relationships, the dissolution of project-based research and development (R\&D) network relationships, etc. [12,25]. Therefore, in order to obtain better network positions, exercise greater influence on partners, and enter foreign market $[5,8]$, VC firms will form valuable network relationships and dissolve redundant network relationships.

The existing research on the mechanisms of VC network evolution is mostly from a single perspective, such as the firm level, dyad level or network level. The research of the firm level mainly focuses on the VC firms' reputation and government background. VC firms choose syndication partners and management relationships according to the resources needed, reputation, and government background, which are important characteristics of VC firms that symbolize the investment ability and government resources of the VC firms [11,19]. The studies of the dyad level mainly focus on the geographic proximity and cognitive proximity between VC firms. Geographic proximity and cognitive 
proximity can alleviate the partner selection risk, improve the network relationship coordination efficiency, and influence the evolution of VC networks [6]. The studies of network levels mainly focus on network embeddedness. Network embedding characterizes the status and relationships of VC firms in the network, which helps them to search the information of potential partners, resulting in a predictable, path-dependent evolution of the VC network [8]. The existing research on the mechanism of the VC network evolution is limited to a single level of factors, such as individual characteristics, binary relations or network structure characteristics, often overlooking multi-level, systematic research.

\section{2. $V C$ and the Clean Energy Industry}

The literature on the relationship between VC and clean energy is relatively lacking. Some studies focus on what factors promote VC firms to invest in clean energy industries. First, VC firms have strong policy risk perception capabilities, while the development prospects and viability of the clean energy industry are strongly dependent on environmental policies, so environmental policies seriously affect the tendency of VC firms to enter the clean energy industry [17]. Second, the improvement of the legitimacy of the clean energy industry enables it to gain recognition and support from governments, regulatory agencies, and external stakeholders, and enhance the confidence of $\mathrm{VC}$ firms and attract more VC firms $[4,6,26]$. Third, the economic environment is a key factor that constrains VC firms' preference for renewable energy and climate policies, as the risk tolerance, rising capital requirements, and borrowing costs of VC firms are closely related to it $[27,28]$.

Some studies focus on the impact of VC on clean energy start-ups and suggest that VC can alleviate the funding gap, improve innovation capabilities, and promote the commercialization of clean energy start-ups [29,30]. Marcus et al. [30] pointed out that VC firms have done more clean energy deals at the early stages. Bürer and Wüstenhagen [29] suggested that VC is particularly important to the innovation chain of clean energy startups as they provide the early stage financing needed for new ventures to launch new clean energy innovations onto the market. Most of the clean energy start-ups are high-risk and high-tech enterprises, and the funding gap hinders the development of their innovation capabilities and the process of commercialization, while their innovation capability is their core competitive factor and commercialization is conducive to their development and survival [29]. VC has the characteristics of high risk, high profit and equity, and it can provide additional value-added services on the basis of providing funds, which help clean energy start-ups to increase their R\&D investment and innovation capability and promote their rapid commercialization [30,31].

However, some studies suggest that VC firms are not suitable for investing in clean energy industries because investments in the clean energy industry are riskier and offer lower returns than investments in other industries, such as the medical and software industries [21]. In addition, VC backing of clean energy startups faces more risks than other industries, due to regulatory uncertainty, gaps in evaluating skills, the long-term investment period, and risky exit opportunities [32]. Regarding policy risk, Criscuolo and Menon [17] suggested that because the profitability prospects of clean energy startups often depend on public regulation, VC firms face greater policy risks when investing in clean energy startups because environmental policy has proved to be remarkably volatile in many countries. Regarding project evaluation risk, Cumming et al. [33] argued that clean energy investment differs from traditional VC industries by virtue of lack of media exposure and fascination, so as to make it more difficult to evaluate the risk and return tradeoff of clean energy VC investments. Petkova et al. [4] argued that due to the lack of a framework for assessing start-ups in the clean energy industry, VC firms face uncertainty in determining the quality and potential of a particular clean energy startup. Regarding liquidity risk, Gaddy et al. [34] argued that VC firms face higher liquidity risks when investing in clean energy industry, as clean energy companies require a longer payback period, from the earlier stage of technology development to the later stage of technology commercialization. Regarding exit risk, Ghosh and Nanda [3] pointed out that one of the most important risks threatening VC invest in clean energy industry is the inability of VC firms to exit their investments at the appropriate time. 


\section{Theoretical Development and Hypotheses}

\subsection{Firm-Level Factors and Network Evolution}

\subsubsection{GVC}

GVC firms are VC firms that are supported by governments to promote the development of emerging industries and high-tech industries and alleviate the market capital allocation failure caused by information asymmetry and R\&D activities [18].

When investing in clean energy start-ups, GVC firms, as attractive syndication partners, have more opportunities to make syndication investments and promote network relationship formation. First, clean energy technology has high R\&D and market risks; additionally, investing in the clean energy industry has the characteristics of a long investment cycle and a large amount of investment capital is needed [3]. Due to concerns about the next round of fundraising, PVC firms are unlikely to invest in clean energy start-ups alone and are more willing to invest in clean energy syndication projects with GVC firms, which have longer time horizons [18]. Second, the energy industry is subject to government regulation and GVC firms have close relationships with governments at all levels. In addition to having access to clean energy start-ups, GVC firms can also provide policy support for clean energy start-ups, such as R\&D subsidies. Therefore, GVC firms are popular partners when investing in clean energy projects.

GVC firms have incentives to dissolve network relationships. First, the function of a GVC firm is to guide PVC firms into the highly uncertain clean energy industry. If only a few PVC firms are syndicated, the leverage function of the GVC firms cannot be fully utilized. Therefore, GVC firms will continuously adjust their syndication partners. Second, due to the strong heterogeneity between GVC firms and PVC firms, there are high agency costs and transaction costs between them, which often cause cooperation friction [19]. Therefore, the network relationship formed by the GVC tends to be disbanded. Based on the above analysis, we propose the following hypotheses:

Hypothesis 1 (H1). GVC firms are more likely to form network relationships.

Hypothesis 2 (H2). GVC firms are more likely to dissolve network relationships.

\subsubsection{Reputation}

The reputation reflects the stakeholders' perceptions of a VC firm's past behavior and future prospects and can ensure that the VC can find and obtain more project sets in an increasingly fierce market [3], helping to raise funds and gain networking and influence [11].

When investing in clean energy start-ups, high-reputation VC firms have higher incentives and more opportunities for investment syndication, thus promoting the formation of network relationships. First, high-reputation VC firms have the pressure to improve their investment performance. As an emerging industry, the clean energy industry is an ideal industry for high-reputation VC firms to make exploratory investment decisions and enhance their reputations. At the same time, to cope with the ambiguity and investment risks, high-reputation VC firms will widely adopt syndication strategies to establish network relationships. Second, due to the signal function of reputation, reputable VC firms can transfer information about their investment capabilities and reliability to potential partners and, thus, can been seen as safer and more promising potential partners, thereby increasing their attractiveness as a syndication partner for investing in clean energy projects [4].

For the dissolution of network relationships, the network relationship formed by high-reputation VC firms tends to remain stable in view of maintaining a good reputation. First, to maintain their reputation, high-reputation VC firms will set stricter screening criteria when selecting syndication partners, requiring potential partners to have higher investment capacity and more expertise regarding clean energy industries, preferring peers with the same high reputation to form syndication 
relationships [11]. The resulting network relationship has a higher value and tends to remain stable. Second, to ensure the performance sustainability, high-reputation VC firms usually adhere to their own choices, strive to maintain the cooperative relationships established in the clean energy industry, and improve the stability of those network relations. Therefore, we propose the following hypotheses:

Hypothesis 3 (H3). High-reputation VC firms are more likely to form network relationships.

Hypothesis 4 (H4). High-reputation VC firms are less likely to dissolve network relationships.

\subsection{Dyad-Level Factors and Network Evolution}

\subsubsection{Geographic Proximity}

Geographic proximity refers to the spatial distance between VC firms, and the external performance is the aggregation of VC firms with their partners. VC firms have certain geographic aggregation needs [35], and most of them are concentrated in specific regions.

When investing in the clean energy industry, geographic proximity fosters link formation because it helps to reduce the cost of information searching and communication between VC firms, and improve the efficiency of information sharing, thus affecting the formation of relationships between VC firms. First, because flows of information decay with increasing distance, geographical proximity is positively related to the efficiency of information dissemination, facilitating the flow of resources and hidden information [36]. Therefore, information about the availability, suitability, and reliability of potential partners will grow with a close geographical proximity, and partner search costs are reduced. Second, geographic proximity facilitates regular communication and mutual trust between VC firms for clean energy startups because it makes frequent face-to-face interactions much easier [35]. Such regular communication and mutual trust are especially important because the risks faced by clean energy startups are high.

As the geographic proximity strongly enhances the efficiency of information dissemination, regular communication, and mutual trust, it may decrease the value of ties and increase the number of alternative partners, which, in turn, will result in quicker network dissolution. First, because geographical proximity is positively related to resource homogeneity, the information and resources owned by geographically adjacent VC firms are likely to be similar, such as the source of VC projects and third-party professional institutions. Thus, the network relationships formed by geographically proximate VC firms hinder the entry of new knowledge and information over time, reducing the scope of information acquisition and the quality of value-added services, leading to a decline in the value of cooperation and a reduction in the likelihood of continued relationships [37]. Second, due to the existence of more alternative partners, the opportunity cost of dissolving the relationship with the geographically close VC firms is lower. Therefore, we propose the following hypotheses:

Hypothesis 5 (H5). Geographic proximity positively influences relationship formation.

Hypothesis 6 (H6). Geographic proximity positively influences relationship dissolution.

\subsubsection{Cognitive Proximity}

Cognitive proximity is the degree of similarity of the expertise of VC firms [38], reflecting the degree of similarity in the perception, assessment, and understanding capabilities of VC firms.

When investing in the clean energy industry, cognitive proximity helps to generate trust among VC firms, improve the efficiency of information transfer and knowledge sharing, and reduce transaction costs, which are conducive to the formation of network relations. First, cognitive proximity will lead to a shared psychological identity, form and strengthen a trusting relationship, reduce uncertainty in 
the process of establishing relationships, and reduce the risk of adverse selection and opportunistic behavior [24]. Second, cognitive proximity facilitates the exchange and transmission of information between VC firms, realizes resource sharing and resource integration, and enhances their willingness to share and absorb information [39]. Finally, cognitive proximity helps improve the communication and coordination efficiency between VC firms, helping to reduce transaction costs and information asymmetry in the syndication process, preventing the "free-riding" behavior that emerged from the logic of collective action.

However, cognitive proximity will increase the competition intensity between VC firms, thus increasing the chances of link dissolution. First, cognitive proximity reduces the flow of heterogeneous and novel information between actors. As the relationship deepens, the resources of the VC firms become more homogeneous and redundant and limit the opportunities to search for new knowledge and learn [40]. Second, as cognitive proximity will increase the market overlap and cause competition for clean energy projects between VC firms, they are more inclined to adopt self-protection strategies and dissolve network relationships [25]. Therefore, we propose the following hypotheses:

Hypothesis 7 (H7). Cognitive proximity positively influences relationship formation.

Hypothesis 8 (H8). Cognitive proximity positively influences relationship dissolution.

\subsection{Network-Level Factors and Network Evolution}

\subsubsection{Structural Embeddedness}

Structure embeddedness refers to the existence of a common partner between organizations [16], that is, the triad structure formed by the three-party relationship. A common third party can monitor partner behavior and provide effective informal governance.

When investing in the clean energy industry, two unconnected VC firms are more likely to form a tie if both have ties with a common third firm, resulting in a closed triad structure. First, to reduce the search costs of finding new partners, using common partners as reliable information intermediaries can increase the visibility of the partner search space [8], transmit timely information about syndication opportunities for clean energy projects, and use professional knowledge to judge potential syndication opportunities, which, in turn, promote the formation of new ties. Second, taking into account the information asymmetry in syndication and the adverse selection risk for new partners, VC firms tied to a common partner can obtain nonpublic information about the capabilities, reliability, and motives of each other [39], which can facilitate network formation.

Consistent with a study by Greve et al. [25], structural embeddedness can help VC firms monitor and enforce syndication relationships. First, the presence of common partners induces social monitoring benefits because it will cause deterrent-based trust. Common partners can spread information regarding the breaking of rules and punish the norm breaker [16]. The social monitoring benefits help to maintain the relationships. Second, the presence of common partners increases the trust and familiarity between VC firms, generates strong emotional commitments, improves efficiency and equality in syndication relationships, and reduces uncertainty in the investment process, thus maintaining relationships. Therefore, we propose the following hypotheses:

Hypothesis 9 (H9). Structural embeddedness positively influences relationship formation.

Hypothesis 10 (H10). Structural embeddedness suppresses relationship dissolution. 


\subsubsection{Positional Embeddedness}

Positional embeddedness relates to the extent to which VC firms occupy a central position in the VC network [16]. It can measure status, which affects the ability of VC firms to obtain and disseminate information, and it is closely related to the behavior and performance of VC firms.

When investing in the clean energy industry, VC firms with central network positions have more opportunities and better capabilities to establish investment syndication relationships. First, VC firms in central network positions have higher status and legitimacy, which help them receive more syndication invitations for clean energy projects, especially from new VC firms that lack investment records [5]. Second, VC firms in central network positions have greater scope than noncentral firms for collecting and disseminating information [15]. The information that is obtained by central VC firms helps them select partners that possess more clean energy expertise and demonstrate reliable collaborative behavior and reduce the costs of searching for partners, negotiating, and monitoring.

VC firms with central network positions have less motivation to maintain too many network relationships. First, as resources and energy are limited, network-centric VC firms with many network relationships and multiple sources of information cannot fully realize reciprocity with all of their partners. Such network relationships that are lacking attention are likely to be dissolved [41]. Second, the power of selecting partners and the informational benefit of collecting and disseminating information that network-centric VC firms possess enhances their opportunity and ability to maintain their privileged positions via the formation of valuable new relationships while dissolving old relationships that have become less valuable. Finally, the power imbalance inherent between central and peripheral VC firms is a source of instability [16]. Therefore, we propose the following hypotheses:

Hypothesis 11 (H11). Positional embeddedness supports relationship formation.

Hypothesis 12 (H12). Positional embeddedness supports relationship dissolution.

Base on the aforementioned analysis, Figure 1 summarizes the theoretical model and research hypotheses.

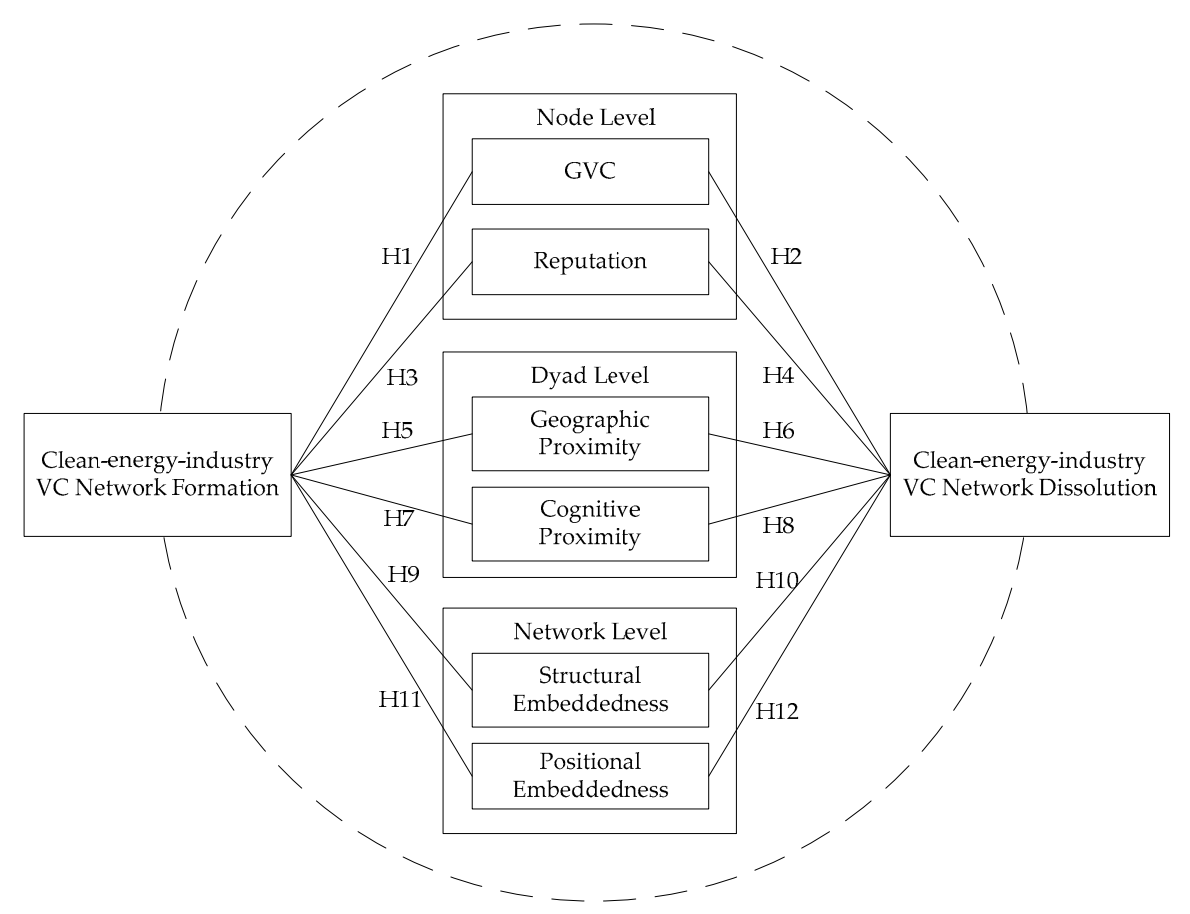

Figure 1. Theoretical model and hypotheses. VC: venture capital; GVC: governmental venture capital. 


\section{Network Dynamic Analysis Methodology—STERGM}

Researchers have previously drawn attention to the longitudinal dynamics of networks [42], which generally utilize longitudinal network data and aim to explain the evolution of relationships. Network dynamics are characterized by two processes: relationship formation and relationship dissolution. Relationship formation expresses the outcomes of node pairs where no relationship exists-they either form or fail to form a tie. Relationship dissolution expresses the outcomes of pre-existing relationships-they either dissolve or persist at the next time point.

A range of network dynamic analysis methods can be applied to identify the factors driving the networks' evolution. The most widely used are the stochastic actor-oriented model (SAOM) and the separable temporal exponential random graph model (STERGM) [43]. These two methods differ in the models' assumptions and mechanics. The SAOM assumes that network evolution is the result of actors measuring the pros and cons of forming edges or dissolving edges according to the rate function and the objective function, so it is called an actor-oriented model. The STERGM, however, in its basic formulation, is a model of the edges in a network. These edges are modeled as a function of the topology of the network itself, exogenous relational covariates, and exogenous vertex (actor) attributes, either concurrently or as a function of past states of the network. The paper chooses the STERGM because its nature as a tool of network dynamic analysis, and its ability to separate formation and dissolution processes. While SOAMs offer similar features, these are achieved by the fundamental assumption of agency residing with the nodes. In other words, the models are built on actor-based behavioral assumptions. When applying these models to inter-organizational or inter-regional networks, this assumption of agency is likely to be violated. Moreover, Leifeld and Cranmer's [43] recent theoretical and empirical comparisons suggest that (S)TERGMs outperform SOAMs, which further motivates the presentation of STERGM for the analysis of clean energy industry VC networks.

We focus on the application of the recently developed STERGM and seek to highlight its three advantages that are crucial in the context of VC networks. The primary advantage of the STERGM is that it can separate network formation and network dissolution processes. In addition, STERGM allows the accurate specification of multiple processes that simultaneously influence the dynamics of the network structure. Finally, STERGM does not need the assumption of independence that underlies conventional models. Obviously, STERGM also has some disadvantages. For example, parameters in the STERGM are strongly dependent on the interval length between two time-points. As a discrete model, STERGM cannot depict the reciprocal influences between these dependent variables. But overall, STERGM is an international frontier research method for modeling dynamic networks, such as spatial networks and communication networks [12,44]. Broekel and Bednarz [12] used STERGM to analyze the evolution of the German biotechnology industry R\&D cooperation network. Fitzhugh and DeCostanza [44] chose STERGM to analyze demographic attribute variables and network structure variables as the driving forces for the evolution of communication networks.

STERGM is a recently developed extension of the exponential-family random graph model (ERGM), which is the current mainstream relationship-oriented social network evolution analysis model [13]. A STERGM shows that a network at time $t$ is conditional on the network at time $t-1$, and it independently analyzes the formation and dissolution of links. A schematic diagram of STERGM is shown in Figure 2. 


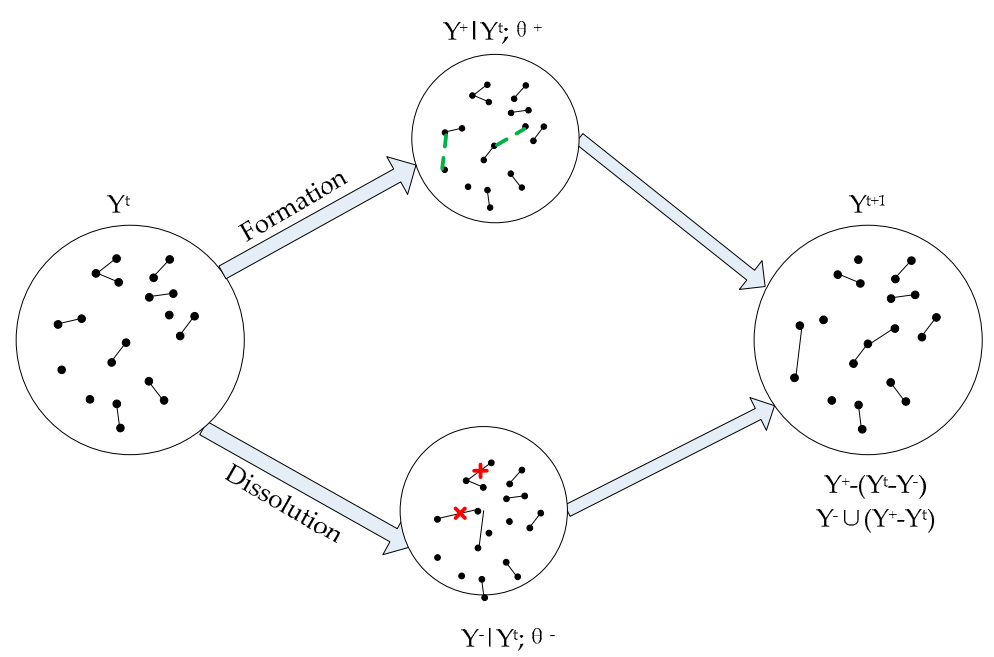

Figure 2. Schematic diagram of the separable temporal exponential random graph model (STERGM).

Accordingly, a STERGM is divided into two formulas: the relations formation formula and the relations dissolution formula.

$$
\begin{aligned}
& \operatorname{Pr}\left(Y^{+}=y^{+} \mid Y^{\mathrm{t}}\right)=\left(\frac{1}{k^{+}}\right) \exp \left\{\left(\theta_{A}^{+}\right)^{t} g_{A}^{\left(y^{+}\right)}\right\}, \\
& \operatorname{Pr}\left(Y^{-}=y^{-} \mid Y^{\mathrm{t}}\right)=\left(\frac{1}{k^{-}}\right) \exp \left\{\left(\theta_{A}^{-}\right)^{t} g_{A}^{\left(y^{-}\right)}\right\},
\end{aligned}
$$

where $k^{+}$and $k^{-}$are normalizing constants that are implemented to ensure a proper probability distribution of the equation. $\theta_{A}^{+}$and $g_{A}^{\left(y^{+}\right)}$are the network configuration $\mathrm{A}$ and the network statistics of relations formation. $\theta_{A}^{-}$and $g_{A}^{\left(y^{-}\right)}$are the network configuration A and the network statistics of relations dissolution. STERGMs allow the inclusion of node, dyad, and structural determinants at the same time.

\section{Research Design}

\subsection{Data and Sample}

The Chinese clean energy industry is exemplified as a sample to research the evolution of a VC network. The data for the empirical analysis were retrieved from Zero2IPO database. This comprehensive database has been extensively used in Chinese VC research [11]. Zero2IPO database provides detailed information on VC firms and VC investment events, especially syndication investment events, in the Chinese clean energy industries. We initially extract information from VC investments in clean energy industries, such as investment date, invested company, investors, and investment amount. Consequently, we collect information such as ownership type, investment experiences, and location based on the name of VC firms.

Although VC investments in China increased rapidly after the late 1990s, the VC investments in the clean energy industry began to emerge after 2000, and syndication investments in the Chinese clean energy industry did not occur until 2006. Therefore, we narrowed down the sample to syndication investments in clean energy industries between 2006 and 2017. Clean energy startups in the database are divided into the following four subsectors: new materials, environmental protection, new energy, and other cleaning technologies. We also collect the investment amount in the whole clean energy industry as well as in the different development stages and subsectors. The final sample contains a total of $603 \mathrm{VC}$ firms and 292 rounds of syndication investment in clean energy startups.

At present, the construction of a VC network is mostly based on syndication investment [4]. Therefore, we constructed the Chinese clean energy industry VC network based on the clean energy 
startups' syndication investment, with the VC firms as the nodes and the syndications as the links. This implies that if two VC firms have a link, they will have invested in one or more common clean energy startups. To account for the potentially time-varying effects of our explanatory variables and the dynamics of VC networks, we use three-year windows to construct the VC network, namely, 2006-2008, 2009-2011, 2012-2014, and 2015-2017.

\subsection{Variables and Measures}

The dependent variable in our study is the formation and dissolution of clean energy industry VC networks. Our key independent variables examine the effect of the VC firm's characteristics at different levels of analysis—firm level, dyad level, and network level—on the subsequent VC network. We also include the variable of edge as the constant term of the traditional regression models, and some VC firm-level variables as control variables. The descriptions and definition of the variables in the STERGM are shown in Table 1.

Table 1. STERGM variables and definitions.

\begin{tabular}{|c|c|c|c|}
\hline Variables & STERGM Term & Diagram $^{1}$ & Definition \\
\hline Edges & edges & & $\begin{array}{c}\text { The number of edges in } \\
\text { the network. }\end{array}$ \\
\hline GVC & nodefactor(GVC) & GVC & $\begin{array}{l}\text { The sum of value of GVC } \\
\text { for all existing edges }(i, j) \\
\text { in the network. }\end{array}$ \\
\hline Reputation & nodecov (Repu) & Repu & $\begin{array}{l}\text { The sum of value of } \\
\text { reputation for all existing } \\
\text { edges }(i, j) \text { in the network. } \\
\text { The sum of the }\end{array}$ \\
\hline Geographic proximity & edgecov (Geo-Prox) & & $\begin{array}{l}\text { geographic proximity for } \\
\text { each edge appearing in } \\
\text { the network. }\end{array}$ \\
\hline Cognitive proximity & edgecov (Cog-Prox) & & $\begin{array}{c}\text { The sum of the cognitive } \\
\text { proximity for each edge } \\
\text { appearing in the } \\
\text { network. }\end{array}$ \\
\hline $\begin{array}{c}\text { Structural } \\
\text { embeddedness }\end{array}$ & GWESP & & $\begin{array}{c}\text { The geometrically } \\
\text { weighted edge shared } \\
\text { partners. }\end{array}$ \\
\hline $\begin{array}{c}\text { Positional } \\
\text { embeddedness }\end{array}$ & GWDegree & & $\begin{array}{l}\text { A geometric statistic that } \\
\text { inversely weighs the } \\
\text { value of degree as a } \\
\text { node's count on statistic } \\
\text { increases. }\end{array}$ \\
\hline Capital source & $\begin{array}{l}\text { Nodefactor } \\
\text { (Capital) }\end{array}$ & Capital & 0: Non-foreign1: Foreign \\
\hline Investment experience & nodecov (Exper) & Exper & $\begin{array}{c}\text { The sum of value of age } \\
\text { for all existing edges }(i, j) \\
\text { in the network. } \\
\text { The sum of value of } \\
\text { investment experience } \\
\text { for all existing edges }(i, j) \\
\text { in the network. }\end{array}$ \\
\hline
\end{tabular}

\footnotetext{
${ }^{1}$ Different colors in the diagram represent different attributes of the nodes. Geo-Prox: geographic proximity; Cog-Prox: cognitive proximity; GWESP: geometrically weighted shared partner.
}

GVC. Following Zhang and Mayes [18], we classified VC firms as GVC firms if they were established by the government, with the main funding resource coming from the government and the 
chief executive officer (CEO) and directors appointed by the government. If VC firms belong to GVC firms, the value is 1 ; otherwise, the value is 0 .

Reputation. Following $\mathrm{Gu}$ and $\mathrm{Lu}$ [11], we measured each VC firm's reputation using its prior performance (i.e., the initial public offering (IPO) event). The cumulative IPO number represents the ability of VC firms to successfully cultivate start-ups and is a significant source of reputation for VC firms. To reduce the heteroscedasticity, the cumulative IPO number was normalized by taking the logarithm.

Geographic proximity. Geographic proximity is reduced to Geo-Prox, which refers to the proximity of VC firms in geospatial space and is measured by the inverse of the geographic distance between VC firms. Following prior research [6], we calculated the geographic proximity through the following steps: first, determine the address of the VC firm's office and the accurate prefecture-level city; second, the linear distance between the prefecture-level cities is used to measure the geographic distance of the VC firms. To reduce the heteroscedasticity, the geographic distance was normalized by taking the logarithm. Finally, the formula for geographic proximity is as follows:

$$
G P_{i j}=10-\ln \left(d_{i j}\right)
$$

where $i$ and $j$ index two different VC firms $i$ and $j$, respectively, and $d$ indicates the linear distance between the prefecture-level cities on behalf of VC firms. The resulting measure ranges from zero to ten, and larger values indicate stronger geographic proximity.

Cognitive proximity. Cognitive proximity is reduced to Cog-Prox, which refers to the similarity of the expertise of VC firms, measured by the opposite of the degree of overlap in the investment fields of VC firms. Drawing on prior research [6], we calculated the cognitive proximity through the following steps: first, we observed each VC firm's distribution of investments across industries; second, we calculated the degree of overlap between the investment fields of two VC firms. The formula for cognitive proximity is as follows:

$$
C P_{i j}=2-\sum\left(p_{i k}-p_{j k}\right)^{2}
$$

where $k$ indexes the industry types, $p$ indicates the proportion of investment a VC firm made in industry $k$. The resulting measure ranges from zero (i.e., for two VC firms with no overlap in their investment patterns) to two (i.e., for firms with identical investment patterns).

Structural embeddedness. We measured the structural embeddedness using a geometrically weighted shared partner (GWESP), which represents the tendency to form a closed triangle structure [13]. A similar measure was adopted by Broekel and Bednarz [12] in their study of the R\&D network evolution. It is possible to measure the local clustering properties of the network. The calculation formula is as follows:

$$
v\left(y, \theta_{t}\right)=e^{\theta_{t}} \sum_{i=1}^{n-2}\left\{1-\left(1-e^{-\theta_{t}}\right)^{i}\right\} E P_{i}(y),
$$

where $E P_{i}(y)$ is the number of edges in $y$ between two nodes that share exactly $i$ neighbors in common; $\theta_{t}$ is a parameter of it.

Positional embeddedness. We measured the positional embeddedness using geometrically weighted degree distribution (GWDegree), indicating the degree distribution of nodes in the network [13]. A similar measure was adopted by Fitzhugh and DeCostanza [44] in their study of the communication network dynamics. The calculation formula is as follows:

$$
u\left(y ; \theta_{s}\right)=e^{\theta_{s}} \sum_{i=1}^{n-1}\left\{1-\left(1-e^{-\theta_{s}}\right)^{i}\right\} D_{i}(y),
$$

where $D_{i}(y)$ presents the degree, which is the number of nodes having the $i$ th edge in their network; $\theta_{s}$ is a parameter of it. 
Edge. The variable edges, which are the structural network variables, should always be included when building network models based on the exponential-family random graph model (ERGM) method [13]. The edges variable indicates the number of edges in the network, which is used to measure the network density; the effect is equivalent to a constant term in the traditional regression models, which is generally without explanation [12].

We also include a set of control variables related to VC firms to account for covariates that may influence the network evolution, including capital sources, age, and investment experience.

Capital sources. Following Yang et al. [45], we divided VC firms into foreign and non-foreign according to the nature of the funders. Specifically, a VC firm with foreign capital is marked as 1; otherwise, it is marked as 0 . Compared with non-foreign VC firms, foreign VC firms are accustomed to syndicate to overcome the liability of foreignness and have more motivation to form network relationships and continuously optimize their network positions.

Age. The VC firm's age is the number of years that have passed since the founding year. When the founding year is unknown, we used the first year in which the VC firm first invested as a proxy for the founding year. Old VC firms are different from young VC firms in their endowment of resources and challenges. Everything else being equal, they have more resources to invest in network relationships than young VC firms [24].

Investment experience. We computed a VC firm's investment experience with the natural logarithm of the total number of VC deals. Investment experience can be a signal of the capability of VC firms, and more investment experience of VC firms may attract more potential partners [11].

In Appendix A, Table A1 presents the descriptions of all the VC firm-level variables; it displays the means and standard deviations of the continuous variables and the proportions of the categorical variables.

\subsection{Empirical Estimation}

There are two processes in STERGM, relational formation and relational dissolution, and we assume that they occur independently of one another within a time step. The network formation model and the network dissolution model are as shown in Equations (7) and (8), respectively.

$$
\begin{aligned}
& \operatorname{logit} P\left(Y_{i j, t+1}=1 \mid y_{i j^{\prime}}^{C} Y_{i j, t}=0\right)=\theta_{\text {edges }}^{+} \delta_{\text {edges }}+\theta_{G V C}^{+} \delta_{G V C}+\theta_{\text {Repu }}^{+} \delta_{\text {Repu }} \\
& +\theta_{\text {Geo-Prox }}^{+} \delta_{G e o-P r o x}+\theta_{\text {Cog-Prox }}^{+} \delta_{\text {Cog-Prox }}+\theta_{\text {Gresp }}^{+} \delta_{\text {Gwesp }}+\theta_{\text {Gwdegree }}^{+} \delta_{\text {Gwdegree }}+\theta_{\text {controls }}^{+} \delta_{\text {controls }} \\
& \operatorname{logitP}\left(Y_{i j, t+1}=1 \mid y_{i j}^{C} Y_{i j, t}=1\right)=\theta_{\text {edges }}^{-} \delta_{\text {edges }}+\theta_{G V C}^{-} \delta_{G V C}+\theta_{\text {Repu }}^{-} \delta_{\text {Repu }} \\
& +\theta_{\text {Geo-Prox }}^{-} \delta_{\text {Geo-Prox }}+\theta_{\text {Cog-Prox }}^{-} \delta_{\text {Cog-Prox }}+\theta_{\text {Gwesp }}^{-} \delta_{\text {Gwesp }}+\theta_{\text {Gwdegree }}^{-} \delta_{\text {Gwdegree }}+\theta_{\text {controls }}^{-} \delta_{\text {controls }}
\end{aligned}
$$

where in Equation (7), the expression is conditional on the tie not existing at the prior time step. $\theta_{G V C^{\prime}}^{+}$ $\theta_{\text {Repu' }}^{+}, \theta_{\text {Geo-Prox }}^{+} \theta_{\text {Cog-Prox }}^{+} \theta_{\text {Gwesp }}^{+} \theta_{\text {Gwdegree }}^{+} \theta_{\text {control }}^{+}$are coefficients in the formation network. In Equation (8), the expression is conditional on the tie existing, and $\theta_{G V C^{\prime}}^{-} \theta_{\text {Repu' }}^{-} \theta_{\text {Geo-Prox }}^{-}, \theta_{\text {Cog-Prox }}^{-} \theta_{\text {Gwesp }}^{-} \theta_{\text {Gwdegree' }}^{-}$ $\theta_{\text {control }}^{-}$are coefficients in the dissolution network. In Equations (7) and (8), $y_{i j}^{C}$ represents the probability of observing an edge between $i$ and $j ; \delta_{G V C}, \delta_{\text {Repu }}, \delta_{G e o-P r o x}, \delta_{C o g-P r o x}, \delta_{G w e s p}, \delta_{G w d e g r e e}$ are independent variables; $\delta_{\text {controls }}$ are the control variables except edges; $\delta_{\text {edges }}$ is the number of edges in the network, and $\theta_{\text {edges }}^{+}$and $\theta_{\text {edges }}^{-}$are equivalent to the constant terms of the traditional regression models.

STERGM uses the Markov chain Monte Carlo maximum likelihood estimation (MCMC-MLE) to estimate the model, so that the final prediction is constantly approaching the real network. We estimated our STERGM using the "tergm" package in the R statistical computing environment. The coefficients of the formation and dissolution model can be understood as odd ratios by taking the exponential. In the formation model, a positive coefficient means that the establishment of a link is more likely. In the dissolution model, positive, significant coefficients favor the preservation of links, while negative coefficients favor dissolution. The information criteria, the Akaike information criterion 
(AIC) and Bayesian information criterion (BIC), can be compared with the lower values to provide additional information on a model's goodness of fit.

We used the STERGM to estimate the three transitions of the networks from one period to the next by estimating separate models for each transition, as shown in Table 2. The STERGM demands the network to have the same sets of nodes in both time periods. The independent variable lags behind the dependent variable for three years. Therefore, in the first STERGM, we explored the impact of the variables in 2006-2008 on the network of 2009-2011. In the second STERGM, we explored the impact of the variables in 2009-2011 on the network of 2012-2014. In the third STERGM, we explored the impact of the variables in 2012-2014 on the network of 2015-2017.

Table 2. STERGM group and data structure.

\begin{tabular}{cccc}
\hline Group & Label & $\begin{array}{c}\text { Time Window of } \\
\text { Variables }\end{array}$ & $\begin{array}{c}\text { Time Window of } \\
\text { Network }\end{array}$ \\
\hline First STERGM & $2006-2008 \sim 2009-2011$ & $2006-2008$ & $2009-2011$ \\
Second STERGM & $2009-2011 \sim 2012-2014$ & $2009-2011$ & $2012-2014$ \\
Third STERGM & $2012-2014 \sim 2015-2017$ & $2012-2014$ & $2015-2017$ \\
\hline
\end{tabular}

\section{Results}

\subsection{Descriptive Analysis}

\subsubsection{The Statistical Analysis of Chinese VC Events in the Clean Energy Industry}

Figure 3 illustrates the VC investment amounts in the clean energy industry of each stage from 2001 to 2017. Before 2006, the investment amount of VC in the clean energy industry is relatively low. Since 2006, the investment amount in the clean energy industry has increased substantially and reached approximately 12,000 million dollars in 2017. Seed stage investment and star-up stage investment grew slowly. Expansion stage investment and mature stage investment increased comparatively fast. This indicates that Chinese VC firms are fairly risk averse and tend to invest in low risk clean energy companies.

Table 3 illustrates the total investment amounts and the proportion of the investment amount in different subsectors and provinces. Clean energy industries are classified as new energy, environmental protection, new materials, and other clean technologies. VC firms distribute the maximized amount of capital money investments-16,518.68 million dollars into new energy industries, and $45.88 \%$ of capital money is obtained by it. In addition, environmental protection, new materials, and other clean technologies occupy $30.70 \%, 21.97 \%$, and $1.45 \%$, respectively. Clean energy companies located in Beijing, Guangdong, and Shanghai obtained the largest amount of VC investment. Among them, the financing amount of clean energy companies located in Beijing reached 4697.65 million dollars and accounted for $13.05 \%$, which is the largest in China.

Table 3. VC investment amounts in different subsectors and provinces.

\begin{tabular}{cccccc}
\hline Subsector & $\begin{array}{c}\text { Investment } \\
\text { Amount (\$, } \\
\text { Million) }\end{array}$ & Proportion (\%) & Province & $\begin{array}{c}\text { Investment } \\
\text { Amount (\$, } \\
\text { Million) }\end{array}$ & Proportion (\%) \\
\hline New Energy & $16,518.68$ & 45.88 & Beijing & 4697.65 & 13.05 \\
Environmental Protection & $11,051.71$ & 30.70 & Guangdong & 4167.64 & 11.58 \\
New Materials & 7910.33 & 21.97 & Shanghai & 2415.75 & 6.71 \\
Other Clean Technologies & 520.56 & 1.45 & Other Provinces & $24,720.24$ & 68.66 \\
Total & $36,001.28$ & 100 & Total & $36,001.28$ & 100 \\
\hline
\end{tabular}




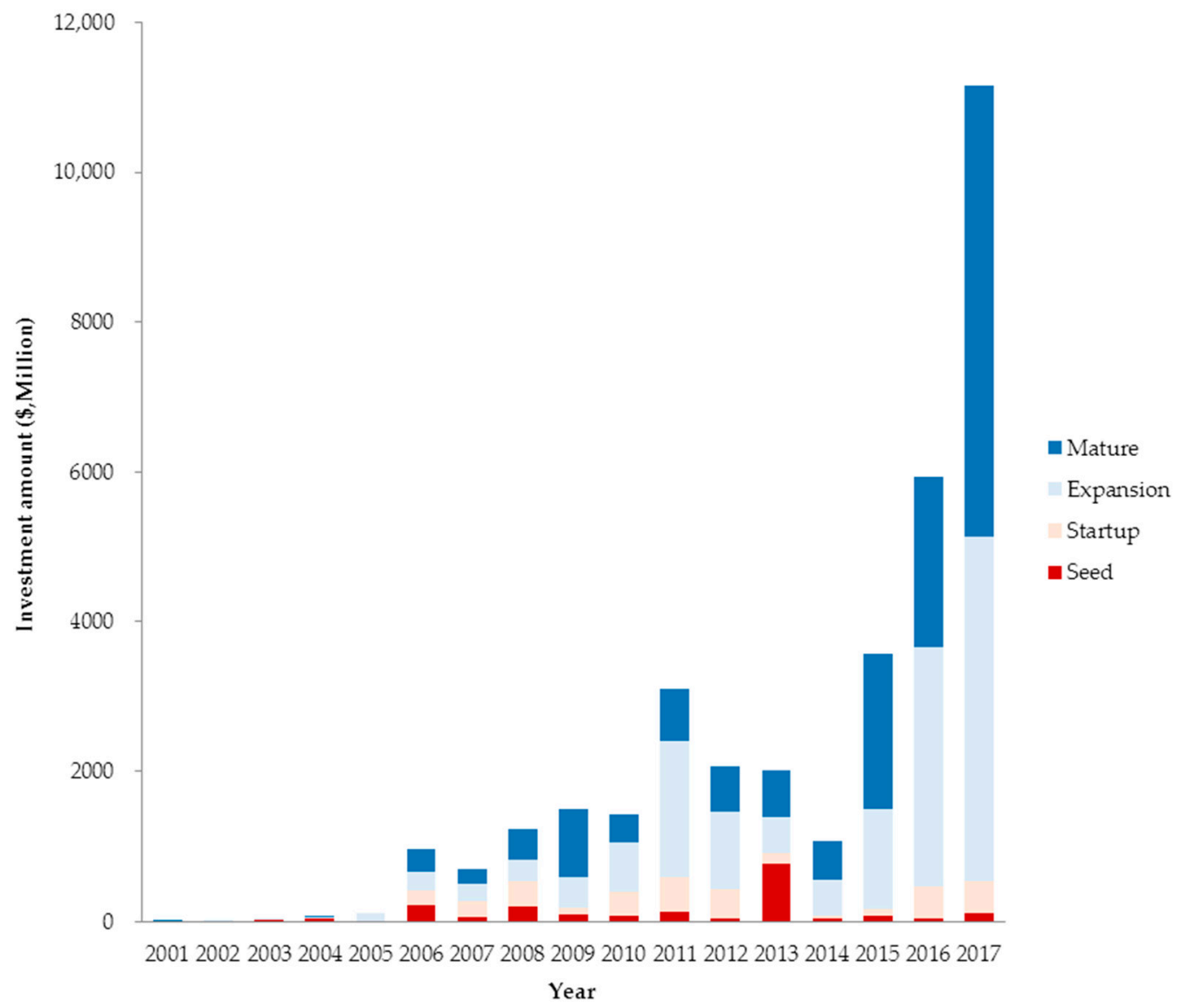

Figure 3. The investment amount of each stage in clean energy industry.

Figure 4 provides a more precise illustration of the proportion of the investment amount in four clean energy subsectors from 2001 to 2017 . The proportion of the investment amount in new energy increased from 2001 to 2005 and has not had a dramatic change since 2006. In the last five years, new energy received the comparatively largest VC investments. The proportion of the investment amount in environmental protection had a dramatic fluctuation in our sample. The investment ratio in new materials tended to drop. Other clean technologies had the smallest proportion among all subsectors. Therefore, it seems that the investment preference of VC firms in the clean energy subsectors varies from time to time. 


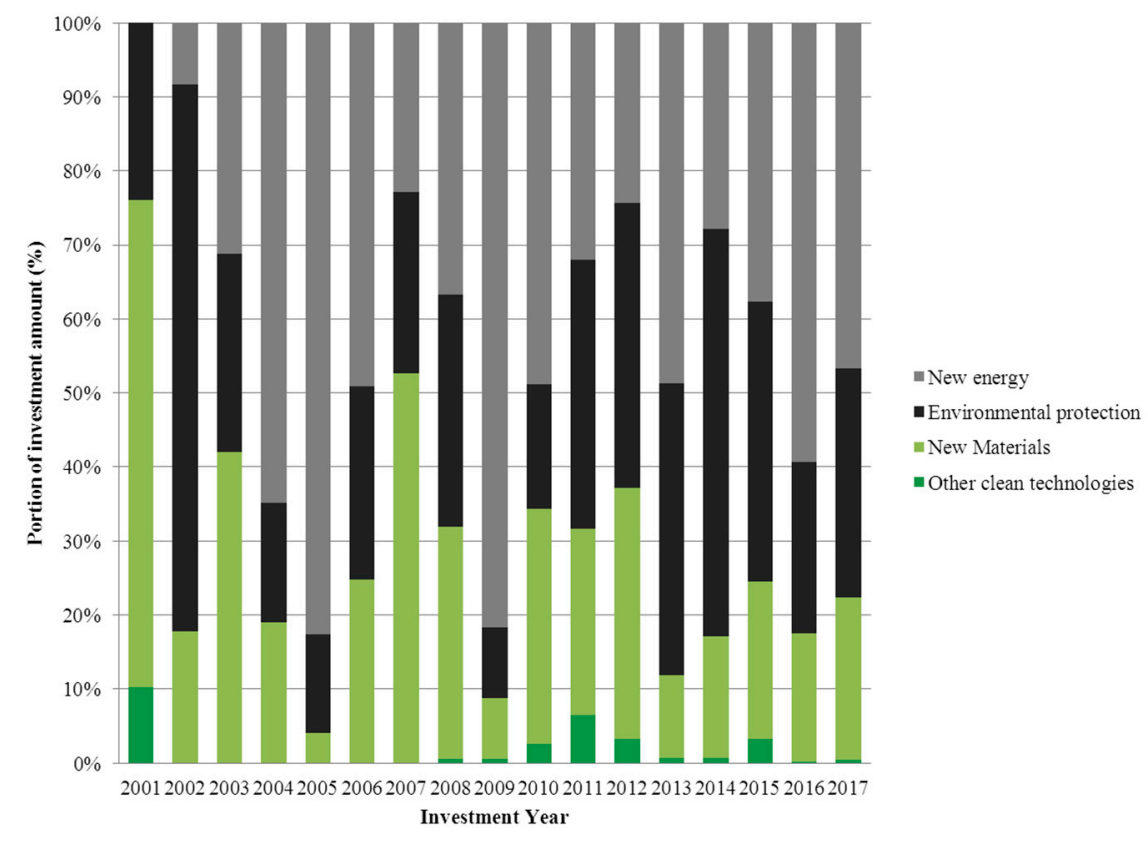

Figure 4. The proportion of investment amount in each clean energy subsector from 2001 to 2017.

\subsubsection{The Structure of the Clean Energy Industry VC Network}

Figure 5 plots the three-year clean energy industry VC networks from 2006 to 2017. In these networks, each node in the plot represents a unique VC firm and an edge is connected by the VC firms which invested jointly in a clean energy startup at any time in the last three years. The number of VC networks significantly boosted from 2015-2017, which indicates that VC firms have a tendency to conduct syndicated investments in clean energy industries.

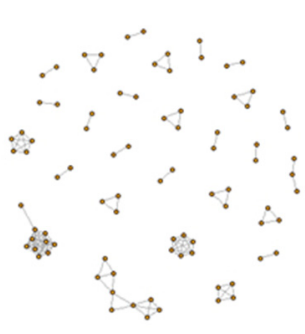

(a) 2006-2008

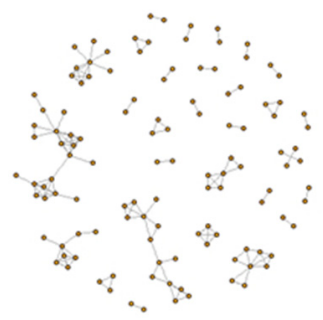

(b) 2009-2011

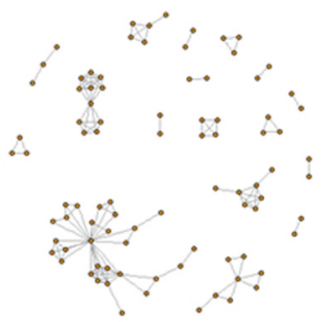

(c) 2012-2014

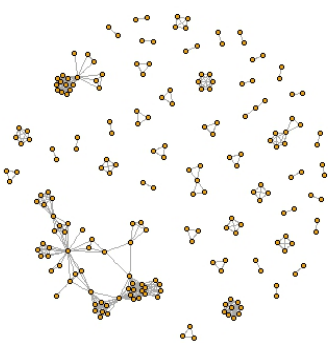

(d) 2015-2017

Figure 5. Evolution of the clean energy industry VC network (2006-2017).

Table 4 summarizes the structural characteristics of each network, including the number of nodes, the number of edges, the network center degree, network connectivity, network modularity, node changes, and edge changes. The network structure shows significant changes, and the specific results are as follows: First, the syndication behavior of VC firms that invest in the clean energy industry is becoming increasingly prominent, and VC firms are paying increasing attention to external knowledge acquisition and resource sharing. The nodes, links, and average degree have increased significantly from 2006 to 2017, except in the network from 2012 to 2014. It shows that the VC networks tend to be optimized. With the increasing emphasis on environmental protection by the Chinese government, the number of investments in the clean energy industry made by VC firms has increased significantly, and the resources and expertise of coordinated VC firms have become an important supporting force for the development of China's clean energy industry. 
Table 4. Network characteristics of the clean energy industry VC network (2006-2017).

\begin{tabular}{ccccc}
\hline Parameters & $\mathbf{2 0 0 6 - 2 0 0 8}$ & $\mathbf{2 0 0 9 - 2 0 1 1}$ & $\mathbf{2 0 1 2 - 2 0 1 4}$ & $\mathbf{2 0 1 5 - 2 0 1 7}$ \\
\hline Nodes & 115 & 222 & 131 & 266 \\
Average degree & 2.000 & 2.514 & 2.977 & 2.797 \\
Connectivity & 0.030 & 0.051 & 0.078 & 0.022 \\
Modularity & 0.914 & 0.910 & 0.837 & 0.907 \\
Links & 115 & 279 & 195 & 372 \\
Nodes added & - & 785 & 75 & 228 \\
Nodes quitted & - & 203 & 166 & 93 \\
Links formed & - & 39 & 117 & 322 \\
Links dissolved & - & 76 & 201 & 145 \\
Links maintained & - & & 78 & 50 \\
\hline
\end{tabular}

Second, the clean energy industry VC network presents community structure but weaker connectivity. The $\mathrm{Q}$ values as the modular index are all greater than 0.8 , indicating that there is a significant "clustering" occurring between VC firms. It shows that VC firms have preferences when choosing syndication partners and the network is characterized by the presence of many relatively small groups of densely interconnected VC firms [24]. The connectivity index is low, which means that the clean energy industry VC networks are generally dispersed, and most VC firms are structurally isolated from one another.

Third, the evolution of the clean energy industry VC networks is in an active phase. In each network, new VC firms entered the network and formed new relationships; at the same time, old VC firms exited the network and dissolved the relationships. In addition, the numbers of new actors and new relationships are greater than the number of exit actors and dissolved relationships, except in the 2012-2014 period, and the VC network expanded rapidly in 2015-2017.

\subsection{Network Formation Analysis}

Table 5 reports the results of VC network formation of Equation (7). There are six sub-models in Table 5, of which models 1, 3, and 5 examine the effects of the control variables on the network formation, and models 2, 4, and 6 examine the effects of the independent variables on the network formation. The positive coefficient indicates the promotion of network relationship formation, and the negative coefficient indicates suppression of network relationship formation.

The coefficients of GVC are significantly positive in model $2(b=0.525, p<0.001)$, model $4(b=0.848$, $p<0.10)$, and model $6(\mathrm{~b}=0.510, p<0.05)$. Accordingly, the GVC firms have more opportunities to make syndication investments and promote the formation of network relationships when investing in the clean energy industry. The findings are consistent with Zhang's [18] conclusion that in China, where the government exerts considerable control over economic and financial development, GVC firms' privileged access to favorable public policies and government contracts attract a large number of syndication partners. Hypothesis 1 is thereby confirmed.

The coefficients of reputation are significantly positive in model $2(b=0.115, p<0.10)$, model $4(\mathrm{~b}=0.606, p<0.05)$, and model $6(\mathrm{~b}=0.113, p<0.05)$. Accordingly, the high-reputation VC firms have higher capabilities to establish network relationships and attract more syndication partners when investing in the clean energy industry. The results confirm with Petkova et al. [4] who found that high reputation VC firms tend to invest in clean energy projects with a widely used syndication strategy to mitigate ambiguity. Hypothesis 3 is thereby confirmed. 
Table 5. Results of the STERGM formation.

\begin{tabular}{|c|c|c|c|c|c|c|}
\hline \multirow{2}{*}{ Variables } & \multicolumn{2}{|c|}{ 2006-2008 2009-2011 } & \multicolumn{2}{|c|}{ 2009-2011 2012-2014 } & \multicolumn{2}{|c|}{ 2012-2014 2015-2017 } \\
\hline & 1 & 2 & 3 & 4 & 5 & 6 \\
\hline Edges & $\begin{array}{c}-5.782^{* * *} \\
(0.170)\end{array}$ & $\begin{array}{c}-6.519 * * * \\
(0.300)\end{array}$ & $\begin{array}{c}-8.061^{* * *} \\
(0.341)\end{array}$ & $\begin{array}{c}-9.936^{* * *} \\
(0.638)\end{array}$ & $\begin{array}{c}-5.414^{* * *} \\
(0.143)\end{array}$ & $\begin{array}{c}-6.731^{* * *} \\
(0.202)\end{array}$ \\
\hline GVC & & $\begin{array}{l}0.525^{* *} \\
(0.174)\end{array}$ & & $\begin{array}{l}0.848+ \\
(0.442)\end{array}$ & & $\begin{array}{l}0.510^{*} \\
(0.234)\end{array}$ \\
\hline Reputation & & $\begin{array}{l}0.115+ \\
(0.068)\end{array}$ & & $\begin{array}{l}0.606 \text { * } \\
(0.307)\end{array}$ & & $\begin{array}{l}0.113 * \\
(0.055)\end{array}$ \\
\hline Geo-Prox & & $\begin{array}{l}1.628 * \\
(0.741)\end{array}$ & & $\begin{array}{c}0.991^{* * *} \\
(0.278)\end{array}$ & & $\begin{array}{l}0.316+ \\
(0.175)\end{array}$ \\
\hline Cog-Prox & & $\begin{array}{l}0.468^{* *} \\
(0.160)\end{array}$ & & $\begin{array}{l}0.365 \text { * } \\
(0.186)\end{array}$ & & $\begin{array}{l}0.468^{* * *} \\
(0.021)\end{array}$ \\
\hline GWESP & & $\begin{array}{c}0.661^{* * *} \\
(0.177)\end{array}$ & & $\begin{array}{c}1.282^{* * *} \\
(0.310)\end{array}$ & & $\begin{array}{c}2.512 * * * \\
(0.112)\end{array}$ \\
\hline GWDegree & & $\begin{array}{c}0.128 \\
(0.211)\end{array}$ & & $\begin{array}{c}0.447 \\
(0.276)\end{array}$ & & $\begin{array}{c}0.188 \\
(0.694)\end{array}$ \\
\hline $\begin{array}{l}\text { Capital } \\
\text { source }\end{array}$ & $\begin{array}{l}0.523+ \\
(0.311)\end{array}$ & $\begin{array}{c}0.462 \\
(0.319)\end{array}$ & $\begin{array}{l}0.445^{*} \\
(0.191)\end{array}$ & $\begin{array}{c}0.918^{* * *} \\
(0.214)\end{array}$ & $\begin{array}{c}-0.570 * \\
(0.274)\end{array}$ & $\begin{array}{c}-0.377^{*} \\
(0.170)\end{array}$ \\
\hline Age & $\begin{array}{l}0.104 * \\
(0.044)\end{array}$ & $\begin{array}{l}0.099 * \\
(0.046)\end{array}$ & $\begin{array}{l}0.316^{* * *} \\
(0.084)\end{array}$ & $\begin{array}{c}0.413^{* * * *} \\
(0.094)\end{array}$ & $\begin{array}{c}0.040 \\
(0.042)\end{array}$ & $\begin{array}{c}0.126 \\
(0.144)\end{array}$ \\
\hline $\begin{array}{l}\text { Investment } \\
\text { experience }\end{array}$ & $\begin{array}{c}0.038 \\
(0.026)\end{array}$ & $\begin{array}{l}-0.039 \\
(0.046)\end{array}$ & $\begin{array}{l}0.090 \text { * } \\
(0.045)\end{array}$ & $\begin{array}{l}0.155+ \\
(0.079)\end{array}$ & $\begin{array}{c}0.007 \\
(0.025)\end{array}$ & $\begin{array}{l}-0.025 \\
(0.018)\end{array}$ \\
\hline AIC & 2877 & 2876 & 874.3 & 838 & 4152 & 4067 \\
\hline $\mathrm{BIC}$ & 3071 & 2929 & 1067 & 890.6 & 4353 & 4122 \\
\hline
\end{tabular}

$+p<0.10 ;{ }^{*} p<0.05 ;{ }^{* *} p<0.01 ;{ }^{* * *} p<0.001$. GWDegree: geometrically weighted degree distribution; AIC: Akaike information criterion; BIC: Bayesian information criterion.

The coefficients of Geo-Prox are significantly positive in model $2(b=1.628, p<0.05)$, model 4 $(b=0.991, p<0.001)$, and model $6(b=0.316, p<0.10)$, indicating that geographical proximity has always played an active role in the formation of relationships among VC firms. Therefore, geographically proximate VC firms tend to form relationships with each other when investing in clean energy start-ups, thus reducing communication costs. The positive relationship between geographically proximate and tie formation is aligned with prior literature arguing that geographic distance impedes partner choice. Taken together, the regression analyses lend support to Hypothesis 5.

The Cog-Prox coefficients gained significantly positive signs in model $2(b=0.468, p<0.01)$, model $4(b=0.365, p<0.05)$, and model $6(b=0.468, p<0.001)$. This confirms the homogeneity hypothesis and means that two VC firms with similar investment experiences are likely to form links when investing in clean energy start-ups. The cognitive proximity will reduce the partner search costs and transaction costs. This finding confirms Du's [46] conclusion that VC firms are more likely to syndicate with partners that are similar to them. Taken together, the regression analyses lend support to Hypothesis 7.

The coefficients of GWESP are significantly positive in model $2(b=0.661, p<0.001)$, model $4(\mathrm{~b}=1.282, p<0.001)$, and model $6(\mathrm{~b}=2.512, p<0.001)$. Accordingly, VC firms with common partners are more likely to form relationships, reducing the cost and uncertainty of searching for new partners. The results are consistent with Gu et al.'s [8] research conclusions on the evolution of China's VC network that VC firms with more common neighbors are more likely to be accepted as partners. Hypothesis 9 is thereby confirmed.

The coefficients of GWDegree are insignificant in model $2(b=0.128$, n.s.), model 4 ( $b=0.447$, n.s.), and model $6(b=0.188$, not significant (n.s.)). Thus, we reject Hypothesis 11 with respect to the link formation model. The possible reason is that as the network connectivity of clean energy industry VC networks in the early stage is low, the VC firms cannot obtain the global information of the network and cannot establish the network relationship according to the firm's degree. 


\subsection{Network Dissolution Analysis}

Table 6 presents the results of the VC network dissolution of Equation (8). There are six sub-models in Table 6, of which models 7, 9, and 11 examine the effects of the control variables on the network dissolution, and models 8,10 , and 12 examine the effects of the independent variables on the network dissolution. The positive coefficient indicates a tendency to maintain the relationship, and the negative coefficient indicates a tendency to dissolve the relationship.

Table 6. Results of the STERGM dissolution.

\begin{tabular}{|c|c|c|c|c|c|c|}
\hline \multirow{2}{*}{ Variables } & \multicolumn{2}{|c|}{ 2006-2008 2009-2011 } & \multicolumn{2}{|c|}{ 2009-2011 2012-2014 } & \multicolumn{2}{|c|}{ 2012-014 2015-2017 } \\
\hline & 7 & 8 & 9 & 10 & 11 & 12 \\
\hline Edges & $\begin{array}{c}-6.650 * * * \\
(0.615)\end{array}$ & $\begin{array}{c}-5.782 * * * \\
(0.965)\end{array}$ & $\begin{array}{c}-7.941 * * * \\
(0.561)\end{array}$ & $\begin{array}{c}-5.315^{* * *} \\
(1.253)\end{array}$ & $\begin{array}{c}-8.323 * * * \\
(0.654)\end{array}$ & $\begin{array}{c}-12.563 \text { * } \\
(5.799)\end{array}$ \\
\hline GVC & & $\begin{array}{c}1.467 \\
(0.936)\end{array}$ & & $\begin{array}{l}-0.302 \\
(0.762)\end{array}$ & & $\begin{array}{c}1.838 \\
(2.205)\end{array}$ \\
\hline Reputation & & $\begin{array}{l}0.026+ \\
(0.015)\end{array}$ & & $\begin{array}{l}0.496+ \\
(0.263)\end{array}$ & & $\begin{array}{l}0.964^{*} \\
(0.457)\end{array}$ \\
\hline Geo-Prox & & $\begin{array}{c}1.160 \\
(0.739)\end{array}$ & & $\begin{array}{c}0.692 \\
(0.597)\end{array}$ & & $\begin{array}{l}-0.663 \\
(1.704)\end{array}$ \\
\hline Cog-Prox & & $\begin{array}{c}-0.498+ \\
(0.300)\end{array}$ & & $\begin{array}{c}-1.096+ \\
(0.557)\end{array}$ & & $\begin{array}{c}-4.353 \text { * } \\
(2.162)\end{array}$ \\
\hline GWESP & & $\begin{array}{l}1.160 * \\
(0.558)\end{array}$ & & $\begin{array}{c}2.002 * * * \\
(0.172)\end{array}$ & & $\begin{array}{l}3.019+ \\
(1.700)\end{array}$ \\
\hline GWDegree & & $\begin{array}{l}-0.016 \\
(0.611)\end{array}$ & & $\begin{array}{r}-0.191 \\
(1.673)\end{array}$ & & $\begin{array}{l}-0.469 \\
(0.614)\end{array}$ \\
\hline $\begin{array}{l}\text { Capital } \\
\text { source }\end{array}$ & $\begin{array}{c}0.149 * * * \\
(0.026)\end{array}$ & $\begin{array}{c}0.378 \\
(0.424)\end{array}$ & $\begin{array}{c}0.045 \\
(1.032)\end{array}$ & $\begin{array}{c}0.228 \\
(1.118)\end{array}$ & $\begin{array}{c}-1.772+ \\
(1.024)\end{array}$ & $\begin{array}{l}-1.989 \\
(4.214)\end{array}$ \\
\hline Age & $\begin{array}{l}-0.104 \\
(0.144)\end{array}$ & $\begin{array}{l}-0.227 \\
(0.180)\end{array}$ & $\begin{array}{c}0.086 \\
(0.155)\end{array}$ & $\begin{array}{c}0.043 \\
(0.742)\end{array}$ & $\begin{array}{c}0.124 \\
(0.214)\end{array}$ & $\begin{array}{c}0.556 \\
(1.299)\end{array}$ \\
\hline $\begin{array}{l}\text { Investment } \\
\text { experience }\end{array}$ & $\begin{array}{l}-0.065 \\
(0.070)\end{array}$ & $\begin{array}{l}-0.099 \\
(0.176)\end{array}$ & $\begin{array}{c}0.067 \\
(0.066)\end{array}$ & $\begin{array}{l}-0.037 \\
(0.147)\end{array}$ & $\begin{array}{c}0.104 \\
(0.071)\end{array}$ & $\begin{array}{l}1.280+ \\
(0.740)\end{array}$ \\
\hline AIC & -56946 & -60728 & -61146 & -65100 & -91379 & -93834 \\
\hline $\mathrm{BIC}$ & -56874 & -60708 & -61067 & -65079 & -91318 & -93818 \\
\hline
\end{tabular}

The coefficients of GVC are insignificant in model $8(b=1.467$, n.s.), model $10(b=-0.302$, n.s.), and model $12(\mathrm{~b}=1.838$, n.s.), indicating that the identity of the GVC has no significant effect on the relationship dissolution. We reject Hypothesis 2 with respect to the link dissolution model. This conclusion shows that a GVC has a conflicting effect on the dissolution of network relations. The reason is that, on the one hand, the heterogeneous syndication investment of GVC firms and PVC firms will cause cooperation friction, which may promote the dissolution of network relationship. On the other hand, when investing in clean energy start-ups, PVC firms urgently need the political connections that GVC firms have; thus, PVC firms will try their best to maintain a network relationship with GVC firms.

The coefficients of reputation are significantly positive in model $8(b=0.026, p<0.10)$, model 10 $(b=0.496, p<0.10)$, and model $12(b=0.964, p<0.05)$. Accordingly, the high-reputation VC firms are more likely to maintain relationships when investing in the clean energy industry. These findings not only confirm Gu's [11] conclusion that reputation is a driving force in the formation of VC network ties, but also extend the literature from an examination of the benefit of reputable VC firms to consideration of the pressure of reputable VC firms. Pressures for consistent performance motivates high-reputation VC firms to adhere to their own choice and maintain network ties. Hypothesis 4 is thereby confirmed.

Geo-Prox was insignificant in model $8(\mathrm{~b}=1.160$, n.s.), model $10(\mathrm{~b}=0.692$, n.s.), and model $12(\mathrm{~b}=-0.663, \mathrm{n} . \mathrm{s}$.$) . This means that there is no significant propensity to sustain or dissolve ties$ between geographically proximate VC firms. We clearly must reject Hypothesis 6 with respect to the 
link dissolution model. The possible reason is that although geographical proximity is conducive to maintaining relationships, the network relationships formed due to geographic proximity have lower values, so geographical proximity has no obvious relationship with network dissolution.

The coefficients of Cog-Prox are significantly negative in model $8(b=-0.498, p<0.10)$, model 10 $(\mathrm{b}=-1.096, p<0.10)$, and model $12(\mathrm{~b}=-4.353, p<0.05)$. Accordingly, the network relationships based on cognitive proximity are not stable. This suggests that resource similarity is conducive to communication when the relationships are formed, but the resource redundancy and competition caused by it hinder the continuity of the relationships. From the evolutionary perspective of the resource-based view, Cui [28] found that the value and uniqueness of a partner's resource will change over time, thus reducing the competitive advantage of the partners and affecting the termination of cooperation. Hypothesis 8 is thereby confirmed.

The coefficients of GWESP are significantly positive in model $8(b=1.160, p<0.05)$, model $10(\mathrm{~b}=2.002, p<0.001)$, and model $12(\mathrm{~b}=3.019, p<0.10)$. Accordingly, structural embedding is conducive to the continuity of the relationship, indicating that the closed triadic structure has sustained and strong stability in the clean energy industry VC networks. These findings are consistent with Polidoro et al.'s [16] conclusion that common third-parties not only facilitate the formation of network relationships, but also enhance the stability of network relationships through shared norms of behavior and social constraints. Hypothesis 10 is thereby confirmed.

The coefficients of GWDegree are insignificant in model $8(b=-0.016$, n.s.), model $10(b=-0.191$, n.s.), and model $12(b=-0.469$, n.s.), indicating that positional embedding has no significant effect on the relationship dissolution. We reject Hypothesis 12 with respect to the link dissolution model. The possible reason is that the clean energy industry VC networks are in the primary stage and lack prominent VC firms; therefore, positional embeddedness has no significant impact on the dissolution of the relationship.

\section{Discussion}

In this article, we try to explore the evolution of China's clean energy industry VC networks from 2006 to 2017 using the STERGM. The results suggest that the formation and dissolution of networks are driven by different factors. Specifically, GVC and geographic proximity have strong impacts on the formation of networks but not on their dissolution. Reputation and structural embeddedness promote the formation of networks and inhibit their dissolution, and cognitive proximity is found to cause network formation while facilitating network dissolution.

Our results are consistent with empirical evidence from Gu et al. [8], who found that using embeddedness theories significantly improved the network dynamic model's predictive power and helped us to uncover mechanisms that affect the formation and dissolution of VC network. However, our results are not in line with existing evidence from Zhang [19] that suggests start-ups backed by PVCs in their initial financing round are more likely to survive to the next round to obtain refinancing, compared to those backed by syndication involving both governmental and private venture capital firms (GVCs and PVCs). The reason may be that GVCs are good at screening clean energy companies with high potential, but not adding value to them.

This paper provides a relatively integrated understanding of network formation by simultaneously examining different levels of factors. Many previous studies have explored the reason for network formation. Some posit that VC network relationship formation follows the pathway of resource dependence, such as GVC identity and high reputation [11,19]. Some argue that VC network relationship formation confirms the proximity theory, such as geographic proximity and cognitive proximity [15]. Others maintain that the VC network structure itself influences the subsequent relationship formation, such as a closed triadic structure [8]. We used the STERGM method to address the impact of three levels of factors on network formation.

This study contributes to the network evolution literature by simultaneously examining network formation and dissolution. Our paper extends the literature by investigating the dissolution of networks 
and thus presents a fairly complete picture of VC network evolution. Our findings are consistent with Kim et al. [42] who point out that network evolution involves the sequential processes of network formation with new partners and the dissolution of network relationships with old partners.

Our research also contributes to the network dissolution literature. The dissolution of networks is an understudied topic in the literature on network evolution. Early scholars often assume that network dissolution is the inverse of network formation, and they have had difficulty obtaining the data of network dissolution. They assume that the factors that lead to network formation naturally prevent network dissolution [47], but rarely conduct empirical research. By showing that network formation and dissolution are driven by asymmetric forces, this study not only contributes to research on network dissolution but also suggests that the dissolution of networks is a more complicated process than previously thought.

Further, our study draws attention to the fact that structural embeddedness provides two related, but distinct types of benefits, and that these benefits map differently onto the outcomes of tie formation and tie dissolution. The first benefit is about referrals, whereby firms are knowledgeable about their partners and regard them as a focal firm [8]. The second benefit is about social restraint [16]. Network formation mainly reflects the referral benefits of having common partners, perhaps combined with some ex ante expectation of social restraint. Network dissolution, on the other hand, offers an opportunity for a closer test of the social restraint mechanism. This result adds further credence to Uzzi's [48] notion of the paradox of embeddedness.

Our finding that the relationships created by the cognitive proximity of VC firms survived for a shorter time is consistent with the prediction of the network competitive frictions theory that competitive overlap between two actors will lead to relationship instability [25]. Competitive overlap exists between two or more firms when they exhibit greater resource similarity and market commonality and have a greater propensity to engage in interfirm rivalry, which is a source of relationship instability. The finding that cognitive proximity promotes relationships formation while accelerating relationships dissolution confirms Polidoro et al.'s [16] point that although firms with similar resources are more likely to become competitors, which is a source of instability, firms also cooperate with peers that have a high level of competitive overlap to reduce transaction costs and improve their absorptive capacity.

In addition to its theoretical contributions, this study highlights one factor contributing to the slow development of the clean energy industry that we have witnessed during the past decade. VC networks help VC firms to improve the quality of their transaction flows, expand the scope of information dissemination, screen outstanding investment projects, and provide more value to start-ups [5]. In the case of the clean energy industry, however, the support provided by the VC network appears to be tempered by its lack of connectivity and elites, as shown in Figure 4. Unlike other industries, the clean energy industry has the characteristics of higher industry barriers, policy dependence, and large amounts of capital are needed [3]. It requires elites to attract more VC firms to enter the clean energy industry and increase the network connectivity to improve the efficiency of the information dissemination of the clean energy industry. Although our findings that GVC firms and reputable VC firms can attract more syndication partners, they only play a role in the local scope and do not increase network connectivity as a whole, which is consistent with the results that positional embeddedness has no significant impact on clean energy industry network's evolution. Therefore, if policymakers and clean energy advocates want to accelerate the development of the industry, they may need to find ways in which to encourage more VC firms to enter the clean energy industry through syndication and give full play to GVC and high reputation VC firms to optimize the structure of the clean energy industry VC network, such as the small-world network with an "elite-clique" [8].

Our study is subject to a number of limitations that can be the starting point for further research. First of all, our sample contains only Chinese VC investments. Although China is the largest developing country in the world and VC investment in clean energy industries is growing rapidly, the institutional environment which affects Chinese VC firms is significantly different from that of the United States and Europe. Conducting a similar study of China, the United States, and European countries would 
examine how these results hold in a different context. A cross-country comparative research would provide more comprehensive evidences on VC networks in clean energy industries. Additionally, the current empirical model ignores the effects of macroeconomic factors on VC investment. Our analysis could address the impact of characteristics of VC firms on network evolution. However, IPO markets, fiscal policies, industry regulation, and economic growth also affect investment risk and return of VC firms and consequently have a significant impact on network evolution. Therefore, an extension of this work may explicitly control the effects of macroeconomic factors, such as IPO numbers, fiscal policies, economic growth, and industry regulation on VC investment in clean energy industries.

Other extensions of this study may examine the impact of the evolution of VC networks on clean technology entrepreneurship or clean technology innovation. It has been proven that VC syndication creates value for entrepreneurial companies in many dimensions. For example, Tian [49] found that VC syndicates nurture innovation of their portfolio companies and help them achieve better post-initial public offering operating performance. Hence, it would also be interesting to study the relationship between VC networks and financing and innovation activities of clean energy companies. Finally, a limitation of our study is the lack of theoretical models. Our paper provides empirical evidence on the dynamic evolution of VC networks but lacks a unified theoretical framework. Wang and Wang [10] provide a theory on the endogenous formation of VC networks in investment syndication. Further studies may apply or develop theoretical models to VC networks in clean energy industries, providing generalizable results.

\section{Conclusions and Policy Implication}

There has recently been a sharp increase in attention to the financing of clean energy companies from VC firms. Based on the STERGM our paper provides evidence for the network development of VC firms investing in clean energy industries. More specifically, the formation of relationships between VC firms does not mean that relationship dissolution is inhibited. In general, before forming relationships, VC firms need to assess the investment philosophy of potential partners and weigh the advantages and disadvantages of different communities. In the VC industry, long-term cooperation can bring more value. This study highlights an additional mechanism through which VC firms can mitigate relationship instability (i.e., reputation and common partners). The benefits from maintaining a good reputation and performance reduce the likelihood of dissolving network relationships. The deterrence-based trust that is promoted by common partners reduces the possibility of dissolving relationships among VC firms.

The rapid development of clean energy industries requires financial support from VC. Therefore, the government should promote the development of the clean energy industry through indirect guidance instead of direct intervention and create a good institutional environment for the development of VC and the clean energy industry while leveraging the VC network to promote the efficient allocation of resources to the clean energy industry.

First, to maximize the positive role of VC in promoting clean energy startups, the government should strengthen the guidance and encouragement of VC to invest in clean energy startups through tax incentives, government guarantees, credit incentives, and flexible exit channels. In particular, the government should strengthen the guidance of GVC firms and give them the right to raise funds from multiple sources, such as introducing more diversified private capital, to expand the amount of GVC funds. Next, the government should reform the incentive mechanism of GVC firms to retain professional talents and increase their competitiveness. Meanwhile, because GVC firms are under the supervision of the State-owned Assets Supervision and Administration Commission (SASAC), the SASAC needs to take account of the high-risk and high-yield characteristics of the VC industry when designing the state-owned assets assessment system.

Second, to promote the efficient allocation of clean energy resources in the VC industry, the government should provide support for establishing and optimizing a close-knit clean energy industry VC network. The government should set up a platform for cooperation and exchange for VC firms 
and publish information related to the clean energy industry, which will help VC firms to conduct more interactions, share investment experience and information, and facilitate syndications with complemental partners.

Third, reputation and structural embeddedness are conducive to the formation and persistence of network relationships, indicating that trust is the basis for the development and maintenance of cooperative behavior. Therefore, the government should establish a professional, independent third-party organization-government departments or business associations-to set up credit information systems and credit files for VC firms, venture capitalists, clean energy startups, and entrepreneurs. Collecting and objectively recording credit information according to law, VC firms can easily understand their partners' and clean energy startups' credit status, which will help VC firms build and maintain syndication relationships and invest in the clean energy industry.

Fourth, the government should provide a good external environment for VC industry development and clean energy start-up growth. The government should establish a legal and regulatory system conducive to the development and utilization of the clean energy industry, integrate incubators and VC to support the development of clean energy start-ups and accelerate the transformation, application, and promotion of their innovations. In addition, the government should focus on the cultivation of professionals in the field of clean energy to deliver high-quality management and R\&D talent to clean energy start-ups.

Author Contributions: Conceptualization, C.Z. and T.P.; methodology, X.D. and C.X.; formal analysis, C.Z. and X.D.; writing—original draft preparation, C.Z. and T.P.; writing—review and editing, C.X. and T.P.

Funding: This research is funded by the National Natural Science Foundation of China (NSFC) under grant no. 71572146; 71702203; 71902157; 71972154. The support is gratefully acknowledged.

Conflicts of Interest: The authors declare no conflicts of interest.

\section{Appendix A}

Table A1. Descriptive statistics of firm-level variables.

\begin{tabular}{cccc}
\hline Variable & Group & Mean or \% & SD \\
\hline GVC & 1 (GVC) & $3.81 \%$ & \\
Reputation & (Non-GVC) & $96.19 \%$ & 1.132 \\
& $2006-2008 \sim 2009-2011$ & 1.247 & 1.131 \\
Capital source & $2009-2011 \sim 2012-2014$ & 1.127 & 0.999 \\
& 2012-2014 2015-2017 & 0.669 & \\
Age & 1 (Foreign) & $18.41 \%$ & 15.551 \\
& 2006-2008 2009-2011 & $81.59 \%$ & 11.028 \\
Investment experience & $2009-2011 \sim 2012-2014$ & 6.110 & 6.622 \\
& $2012-2014 \sim 2015-2017$ & 5.249 & 1.779 \\
& $2006-2008 \sim 2009-2011$ & 2.731 & 1.807 \\
& $2009-2011 \sim 2012-2014$ & 2.662 & 1.644 \\
\hline
\end{tabular}

\section{References}

1. Ari, I.; Koc, M. Sustainable financing for sustainable development: Agent-based modeling of alternative financing models for clean energy investments. Sustainability 2019, 11, 1967. [CrossRef]

2. Shindina, T.; Streimikis, J.; Sukhareva, Y.; Nawrot, Ł. Social and economic properties of the energy markets. Econ. Sociol. 2018, 11, 334-344. [CrossRef]

3. Ghosh, S.; Nanda, R. Venture Capital Investment in the Clean Energy Sector. SSRN. 2010. Available online: https: //www.hbs.edu/faculty/Publication\%20Files/11-020_0a1b5d16-c966-4403-888f-96d03bbab461.pdf (accessed on 8 November 2019). [CrossRef] 
4. Petkova, A.P.; Wadhwa, A.; Yao, X.; Jain, S. Reputation and decision making under ambiguity: A study of U.S. Venture Capital Firms investments in the emerging clean energy sector. Acad. Manag. J. 2014, 57, 422-448. [CrossRef]

5. Hochberg, Y.V.; Ljungqvist, A.; Lu, Y. Whom you know matters: Venture capital networks and investment performance. J. Financ. 2007, 62, 251-301. [CrossRef]

6. Sorenson, O.; Stuart, T.E. Bringing the context back in: Settings and the search for syndicate partners in venture capital investment networks. Adm. Sci. Q. 2008, 53, 266-294. [CrossRef]

7. Kogut, B.; Urso, P.; Walker, G. Emergent properties of a new financial market: American venture capital syndication, 1960-2005. Manag. Sci. 2007, 53, 1181-1198. [CrossRef]

8. Gu, W.; Luo, J.; Liu, J. Exploring small-world network with an elite-clique: Bringing embeddedness theory into the dynamic evolution of a venture capital network. Soc. Netw. 2019, 57, 70-81. [CrossRef]

9. Xue, C.; Jiang, P.; Dang, X. The dynamics of network communities and venture capital performance: Evidence from China. Financ. Res. Lett. 2019, 28, 6-10. [CrossRef]

10. Wang, L.; Wang, S. Economic freedom and cross-border venture capital performance. J. Empir. Financ. 2012, 19, 26-50. [CrossRef]

11. Gu, Q.; Lu, X. Unraveling the mechanisms of reputation and alliance formation: A study of venture capital syndication in China. Strateg. Manag. J. 2014, 35, 739-750. [CrossRef]

12. Broekel, T.; Bednarz, M. Disentangling link formation and dissolution in spatial networks: An application of a two-mode STERGM to a project-based R\&D network in the German biotechnology industry. Netw. Spat. Econ. 2018, 18, 677-704.

13. Krivitsky, P.N.; Handcock, M.S. A separable model for dynamic networks. J. R. Stat. Soc. Ser. B Stat. Methodol. 2014, 76, 29-46. [CrossRef] [PubMed]

14. Ji, Q.; Zhang, D. How much does financial development contribute to renewable energy growth and upgrading of energy structure in China? Energy Policy 2019, 128, 114-124. [CrossRef]

15. Dimov, D.; Milanov, H. The interplay of need and opportunity in venture capital investment syndication. J. Bus. Ventur. 2010, 25, 331-348. [CrossRef]

16. Polidoro, F.; Ahuja, G.; Mitchell, W. When the social structure overshadows competitive incentives: The effects of network embeddedness on joint venture dissolution. Acad. Manag. J. 2011, 54, 203-223. [CrossRef]

17. Criscuolo, C.; Menon, C. Environmental policies and risk finance in the green sector: Cross-country evidence. Energy Policy 2015, 83, 38-56. [CrossRef]

18. Zhang, Y.; Mayes, D.G. The performance of governmental venture capital firms: A life cycle perspective and evidence from China. Pac. Basin Financ. J. 2018, 48, 162-185. [CrossRef]

19. Zhang, Y. Gain or pain? New evidence on mixed syndication between governmental and private venture capital firms in China. Small Bus. Econ. 2018, 51, 995-1031. [CrossRef]

20. Barroco, J.; Herrera, M. Clearing barriers to project finance for renewable energy in developing countries: A Philippines case study. Energy Policy 2019, 135, 111008. [CrossRef]

21. Kharlamova, G.; Chernyak, O.; Nate, S. Renewable energy and security for Ukraine: Challenge or smart way? J. Int. Stud. 2016, 9, 88-115. [CrossRef] [PubMed]

22. Miller, L.; Carriveau, R. A review of energy storage financing-Learning from and partnering with the renewable energy industry. J. Energy Storage 2018, 19, 311-319. [CrossRef]

23. Mazzucato, M.; Semieniuk, G. Financing renewable energy: Who is financing what and why it matters. Technol. Forecast. Soc. 2018, 127, 8-22. [CrossRef]

24. Bubna, A.; Das, S.R.; Prabhala, N. Venture capital communities. J. Financ. Quant. Anal. 2019, 1-73. [CrossRef]

25. Greve, H.R.; Baum, J.A.C.; Mitsuhashi, H.; Rowley, T.J. Built to last but falling apart: Cohesion, friction, and withdrawal from interfirm alliances. Acad. Manag. J. 2010, 53, 302-322. [CrossRef]

26. Kasperowicz, R.; Pinczyński, M.; Khabdullin, A. Modeling the power of renewable energy sources in the context of classical electricity system transformation. J. Int. Stud. 2017, 10, 264-272. [CrossRef]

27. Hofman, D.M.; Huisman, R. Did the financial crisis lead to changes in private equity investor preferences regarding renewable energy and climate policies? Energy Policy 2012, 47, 111-116. [CrossRef]

28. Tvaronavičienè, M.; Prakapienè, D.; Garškaitè-Milvydienė, K.; Prakapas, R.; Nawrot, Ł. Energy efficiency in the long-run in the selected European countries. Econ. Sociol. 2018, 11, 245-254. [CrossRef] [PubMed]

29. Bürer, M.J.; Wüstenhagen, R. Which renewable energy policy is a venture capitalist's best friend? Empirical evidence from a survey of international cleantech investors. Energy Policy 2009, 37, 4997-5006. [CrossRef] 
30. Marcus, A.; Malen, J.; Ellis, S. The promise and pitfalls of venture capital as an asset class for clean energy investment: Research questions for organization and natural environment scholars. Organ. Environ. 2013, 26, 31-60. [CrossRef]

31. Bocken, N.M.P. Sustainable venture capital—Catalyst for sustainable start-up success? J. Clean. Prod. 2015, 108, 647-658. [CrossRef]

32. Simionescu, M.; Bilan, Y.; Krajňáková, E.; Streimikiene, D.; Gędek, S. Renewable energy in the electricity sector and GDP per capita in the European Union. Energies 2019, 12, 2520. [CrossRef]

33. Cumming, D.; Henriques, I.; Sadorsky, P. ‘Cleantech' venture capital around the world. Int. Rev. Financ. Anal. 2016, 44, 86-97. [CrossRef]

34. Gaddy, B.E.; Sivaram, V.; Jones, T.B.; Wayman, L. Venture capital and cleantech: The wrong model for energy innovation. Energy Policy 2017, 102, 385-395. [CrossRef]

35. Bender, M. Impact of Spatial Proximity throughout the Venture Capital Investment Process. In Spatial Proximity in Venture Capital Financing: A Theoretical and Empirical Analysis of Germany; Bender, M., Ed.; Gabler: Wiesbaden, Germany, 2011; pp. 133-186.

36. Reuer, J.J.; Lahiri, N. Searching for alliance partners: Effects of geographic distance on the formation of R\&D collaborations. Organ. Sci. 2013, 25, 283-298.

37. Gompers, P.A.; Mukharlyamov, V.; Xuan, Y. The cost of friendship. J. Financ. Econ. 2016, 119, 626-644. [CrossRef]

38. Nooteboom, B. Learning by interaction: Absorptive capacity, cognitive distance and governance. J. Manag. Gov. 2000, 4, 69-92. [CrossRef]

39. Ter Wal, A.L.J.; Alexy, O.; Block, J.; Sandner, P.G. The best of both worlds: The benefits of open-specialized and closed-diverse syndication networks for new ventures success. Adm. Sci. Q. 2016, 61, 393-432. [CrossRef] [PubMed]

40. Cui, A.S. Portfolio dynamics and alliance termination: The contingent role of resource dissimilarity. J. Market. 2013, 77, 15-32. [CrossRef]

41. Jääskeläinen, M.; Maula, M.; Seppä, T. Allocation of attention to portfolio companies and the performance of venture capital firms. Entrep. Theory Pract. 2006, 30, 185-206. [CrossRef]

42. Kim, T.-Y.; Oh, H.; Swaminathan, A. Framing interorganizational network change: A network inertia perspective. Acad. Manag. Rev. 2006, 31, 704-720. [CrossRef]

43. Leifeld, P.; Cranmer, S.J. A theoretical and empirical comparison of the temporal exponential random graph model and the stochastic actor-oriented model. arXiv 2015, arXiv:1506.06696. [CrossRef]

44. Fitzhugh, S.M.; DeCostanza, A.H. Procure, persist, perish: Communication tie dynamics in a disrupted task environment. Soc. Netw. Anal. Min. 2018, 8, 37. [CrossRef]

45. Yang, S.; Li, Y.; Wang, X. Cohesiveness or competitiveness: Venture capital syndication networks and firms' performance in China. J. Bus. Res. 2018, 91, 295-303. [CrossRef]

46. Du, Q. Birds of a feather or celebrating differences? The formation and impacts of venture capital syndication. J. Empir. Financ. 2016, 39, 1-14. [CrossRef]

47. Yue, L.Q. Asymmetric effects of fashions on the formation and dissolution of networks: Board interlocks with internet companies, 1996-2006. Organ. Sci. 2011, 23, 1114-1134. [CrossRef]

48. Uzzi, B. Social structure and competition in interfirm networks: The paradox of embeddedness. Adm. Sci. Q. 1997, 42, 35-67. [CrossRef]

49. Tian, $X$. The role of venture capital syndication in value creation for entrepreneurial firms. Rev. Financ. 2012, 16, 245-283. [CrossRef]

(C) 2019 by the authors. Licensee MDPI, Basel, Switzerland. This article is an open access article distributed under the terms and conditions of the Creative Commons Attribution (CC BY) license (http://creativecommons.org/licenses/by/4.0/). 